- The index and middle finger regions were assessed to have a significantly higher puncture resistance than the other glove regions. However, this may be less relevant in the dental surgery since clinically these regions, along with the thumb region, were assessed to be CPD PAPER the most common location for glove punctures.

- For all glove types/pentrometer combinations investigated, puncture resistance increased on aging the samples to mimic clinical usage when gloves are routinely worn. The stiffness values evaluated were significantly lower for the latex gloves type assessed compared with the three nitrile glove types investigated.

- The results of the current study indicate that nitrile gloves offer the clinicians that have experienced an adverse reaction to natural latex gloves comparable resistance to puncture with latex gloves.

\title{
Puncture resistance and stiffness of nitrile and latex dental examination gloves
}

\author{
H. B. Patel ${ }^{1}$, G. J. P. Fleming ${ }^{2}$ and F. J. T. Burke ${ }^{3}$
}

Objective The aim of the current study was to assess the puncture resistance and stiffness of nitrile and latex dental examination gloves. Methods Puncture resistance was measured by employing an adapted version of ASTM F1342-91 using both a 316 stainless steel puncture probe ( $0.8 \mathrm{~mm}$ diameter) and a dental injection needle $(0.45 \mathrm{~mm}$ diameter) interfaced to a tensile testing apparatus. Glove specimens (12 cm length, $1.5 \mathrm{~cm}$ breadth) were removed for modulus (M100) evaluation by assessing the force required to elongate the specimen to $100 \%$ of the original length. Glove samples were also aged to investigate whether puncture resistance and $\mathrm{M} 100$ values varied with aging at $70^{\circ} \mathrm{C}$ for 7 days in an air-circulating oven.

Results The nitrile glove types were assessed to have significantly higher puncture resistance compared with the latex glove type when the steel puncture probe was the pentrometer when using the one way analysis of variance (ANOVA) at the 95\% significance level. Interestingly the puncture resistance for the latex glove type was significantly higher $(P<0.001)$ when a dental injection needle was used as the pentrometer compared with the nitrile glove types. The M100 values were significantly higher for the nitrile glove types for which the stiffness increased when the gloves were aged $(P<0.001)$.

Conclusions The higher stiffness values resulted in increased puncture resistance when the nitrile glove specimens were aged irrespective of the pentrometer type. However, the ability of latex to re-seal itself on puncture may be beneficial when considering the protection potential of each glove type against breaches in cross infection. For clinicians that have experienced an adverse reaction to natural latex gloves, the results of the current study indicate that nitrile gloves are available at reasonable cost and offer the clinician comparable resistance to puncture with latex gloves.

${ }^{1}$ Dental Student, ${ }^{2}$ Lecturer in Dental Biomaterials, , Biomaterials Unit, ${ }^{3}$ Professor, Primary Dental Care Research Group, School of Dentistry, University of Birmingham, St. Chad's Queensway, Birmingham B4 6NN

${ }^{*}$ Correspondence to: Garry J. P. Fleming, Biomaterials Unit, The University of Birmingham School of Dentistry, St. Chad's Queensway, Birmingham B4 6NN

E-Mail: G.J.Fleming@bham.ac.uk

\section{Refereed Paper}

doi:10.1038/sj.bdj.4811353

Received 11.11.02; Accepted 29.04.03

$\odot$ British Dental Journal 2004; 196: 695-700
Cleveland et al. ${ }^{1}$ defined percutaneous injuries as visible penetrations of the skin caused by a needle or other sharp instrument and, as highlighted by Palmer and Fleming, ${ }^{2}$ any member of the dental team is at risk of accidental injury when handling sharp or rotating instruments. The surface of the skin or mucous membrane can be damaged, potentially allowing blood to blood or blood to saliva contact between the healthcare professional and the patient. Gloves provide a barrier that may prevent pathogens present in the patient's mouth coming into contact with micro-abrasions on the hands of the healthcare professionals. ${ }^{2}$ However, the barrier function may be challenged by instruments such as needles and other contaminated sharp instruments, possibly causing percutaneous injury and thus providing a means of inoculation.

Since $1987^{3}$ operators began to treat body fluids from patients as though they were infected, and this concept, described by the Centre for Disease Control and Prevention, ${ }^{3-4}$ became known as 'universal precautions'. The asymptomatic nature of some blood borne diseases, namely HIV, hepatitis B and hepatitis C, resulted in the incorporation of 'universal precautions' into a rule in the blood borne pathogens standards by the Occupational Safety and Health Administration in $1991 .^{5}$

Failure of dental examination gloves to provide barrier function thereby allowing body fluid from the patient to contact any cuts or micro-lesions on the dental workers hands can occur from pre-existing pinholes and/or defects that occur during clinical use. Pinhole defects may be inherent to the glove following manufacturing and packaging processes, however, glove punctures are likely to occur during clinical use due to stresses encountered in manipulation and perforations made by sharp teeth or dental instruments. ${ }^{6-9}$ Siew et al. ${ }^{10}$ assessed the incidence of percutaneous injuries in a survey of 2,304 randomly selected US dentists over a 20-day period and 21\% of dentists (480) observed one or more percutaneous injuries in the time frame. Of the 527 categorised percutaneous injuries 37\% (196/527) were attributed to a dental bur, with sharp instruments and syringe needles reported as causing 32\% (170/527) and 17\% (88/527) of the injuries, respectively. Further studies ${ }^{6,11-13}$ have identified the thumb, index or middle finger as being the prone sites for pinhole defects following the use of sharp instruments during glove use. It was proposed by Patton et al. ${ }^{13}$ that during use tension, long fingernails and other factors not discussed by the author might place increased stresses on the glove fingertips. These studies ${ }^{6,11-13}$ highlight the consider- 
able risk of glove puncture in use in the dental surgery especially at the thumb, index or middle finger.

Natural rubber latex, which consists of an emulsion of polymer in water, is the major constituent of the examination gloves used in dentistry and medicine ${ }^{14}$ because of its strength, elasticity, tear resistance and excellent barrier protection properties. ${ }^{15}$ Natural latex may be composed of natural rubbers that contain polypeptides that have the potential to cause hypersensitivity and some type of allergic response. ${ }^{16}$ The most prevalent clinical form of latex allergy is manifested as contact dermatitis, which is a nonallergenic cutaneous response to prolonged glove exposure combined with sweating and abrasion that is exacerbated following routine wearing of gloves for long periods of time. ${ }^{16-17}$ As a result of these associated adverse skin reactions to latex, dental glove manufacturers have produced dental examination gloves from synthetic latex, with the introduction of polyvinyl chloride (PVC) and, more recently, nitrile gloves.

PVC gloves are prone to pre-existing pinhole defects, ${ }^{18}$ exhibit a low puncture resistance ${ }^{19}$ and are reported to significantly decrease in integrity under the stresses of clinical use compared with latex gloves. ${ }^{20}$ Therefore nitrile gloves have been considered a possible alternative to dental gloves manufactured from natural latex, especially for use by those individuals allergic to latex protein. ${ }^{15}$ Nitrile gloves are formed from an emulsion in water often referred to as synthetic latex and are made of a synthetic co-polymer of acrylonitrile and butadiene. ${ }^{21}$ Anecdotal evidence suggests that the flexibility, comfort and fit of nitrile gloves are inferior to latex. However, nitrile gloves are reported to offer better puncture resistance compared with latex gloves. ${ }^{15}$ Unfortunately this anecdotal evidence ${ }^{15}$ does not further the scientific literature on the subject and provides healthcare professionals with inadequate information regarding the properties of nitrile gloves and their resultant performance in clinical practice.

The aim of the current study was to assess the puncture resistance and stiffness of a range of nitrile examination gloves compared with commonly employed latex glove types that may increase the susceptibility of the healthcare professional to contact dermatitis.

\section{METHOD AND MATERIALS:}

\section{Puncture resistance}

\section{Specimen preparation}

Three nitrile dental examination glove types: Safeskin nitrile, Nitratouch nitrile, Microtouch nitrile, and one latex glove type: Microtouch latex were assessed for puncture resistance (Table 1). A total of ten gloves for each glove type were examined and all gloves were chosen from the same batch to eliminate batch/batch variation from the glove populations sampled. From each glove finger two square shaped specimens $(2 \mathrm{~cm}$ width, $2 \mathrm{~cm}$ height) were removed from the tips of both sides of the finger and a third specimen was taken directly below the initial specimen as shown in Figure 1. For the palm area one square shaped specimen $(2 \mathrm{~cm}$ width, $2 \mathrm{~cm}$ height) was removed from both sides at the position also indicated in Figure 1, in an attempt to assess all regions of the gloves for puncture resistance.

\section{Specimen testing}

Steel puncture probe

Puncture resistance was measured by employing an adapted version of ASTM (American Standard for Testing Materials) F1342-91, ${ }^{22}$ which has been commonly used for evaluating the resistance to puncture of protective clothing material. A 316 stainless steel puncture probe, fabricated from steel (Rockwell hardness 35-40) was driven by a tensile-testing machine (Instron model 5544, Buckinghamshire, England) to penetrate the glove specimens. The glove specimens were held within two aluminium support plates of
Table 1 Glove specifications and manufacturer details of three nitrile and one latex glove types investigated

\begin{tabular}{|c|c|c|}
\hline Dental glove type & Batch number & Manufacturer details \\
\hline $\begin{array}{l}\text { Microtouch latex } \\
\text { powdered }\end{array}$ & 0105061721 & $\begin{array}{l}\text { Ansell Healthcare } \\
\text { Products (Malaysia) }\end{array}$ \\
\hline $\begin{array}{l}\text { Microtouch nitrile } \\
\text { powder free }\end{array}$ & 0108003959 & $\begin{array}{l}\text { Ansell Healthcare } \\
\text { Products (Malaysia) }\end{array}$ \\
\hline Nitratouch powder free & 0101203228 & $\begin{array}{l}\text { Ansell Medical } \\
\text { (Thailand) }\end{array}$ \\
\hline $\begin{array}{l}\text { Safeskin blue (nitrile) } \\
\text { powder free }\end{array}$ & $10655-1$ & $\begin{array}{l}\text { Safeskin Corp } \\
\text { (California) } \\
\text { Made in Thailand }\end{array}$ \\
\hline
\end{tabular}

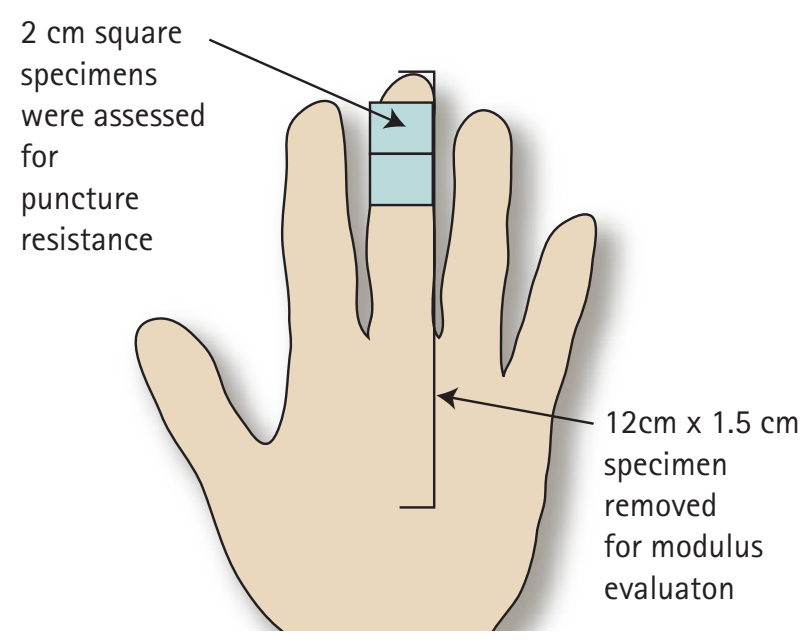

Fig. 1 Diagrammatic representation of specimens removed from each glove type investigated to evaluate puncture resistance and Modulus (M100)

$11 \mathrm{~cm}$ diameter with three $0.6 \mathrm{~cm}$ holes positioned at each peak of an equilateral triangle $2 \mathrm{~cm}$ from the plate mid point (Fig. 2). Following placement of the dental examination glove specimens over the holes on the bottom plate, both plates were clamped together using two pins and two screws. The pins were positioned $3 \mathrm{~cm}$ from the edge of the plate, the screws of $0.8 \mathrm{~cm}$ diameter were placed $1.5 \mathrm{~cm}$ from the plate edge. The $0.8 \mathrm{~mm}$ diameter puncture probe, connected to a $100 \mathrm{~N}$ load cell, was interfaced with a computer and brought to within touching distance of the glove specimen, indicated by the first fluctuation in force recorded by the computer. The force recorded was returned to zero and the punc-

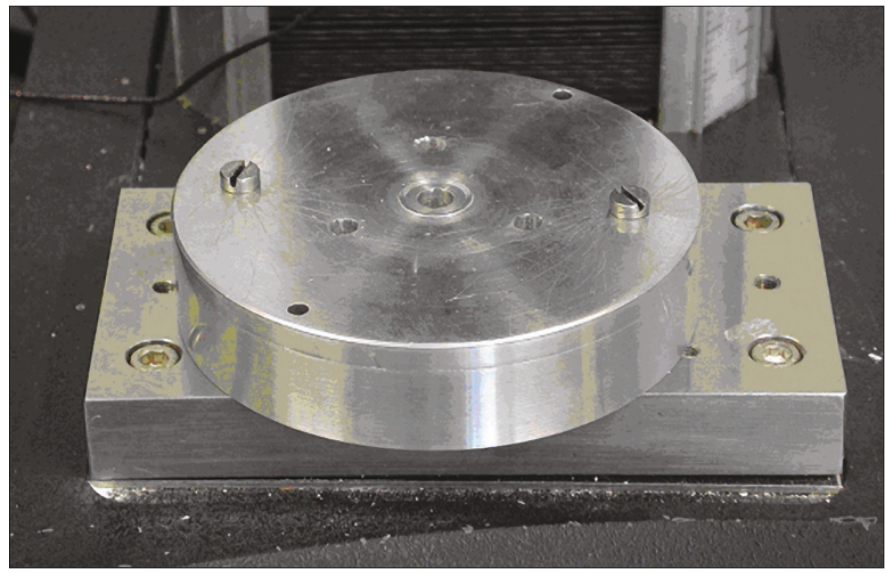

Fig. 2 Aluminium support plates holding three $2 \mathrm{~cm} \times 2 \mathrm{~cm}$ glove specimens which were sequentially punctured with the use of both a steel puncture probe and a hypodermic needle attached to the tensile testing machine to assess maximum force to puncture 


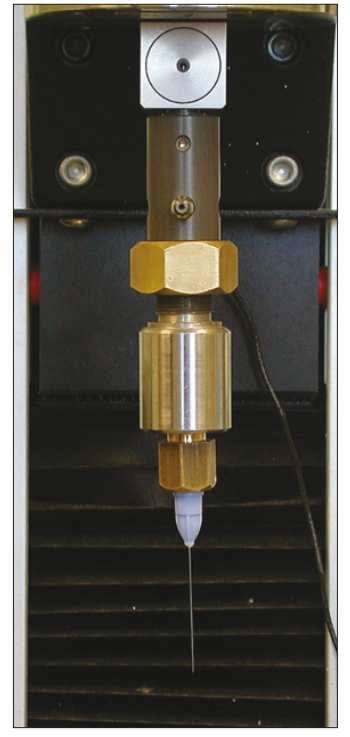

Fig. 3 (above) Apparatus used to assess the puncture resistance of dental examination gloves with a $0.4 \mathrm{~mm}$ diameter disposable sterile dental injection needle connected to the upper arm of the tensile testing machine

Fig. 4 (below) Photograph of the apparatus used to assess the Modulus (M100) of the glove specimens. The push fit brackets attached to the specimen to the upper and lower arms of the tensile testing machine that was fixed at a cross-head speed $100 \mathrm{~mm} \mathrm{~min}^{-1}$ with the gauge length, namely the distance between the brackets, set to $10 \mathrm{~cm}$

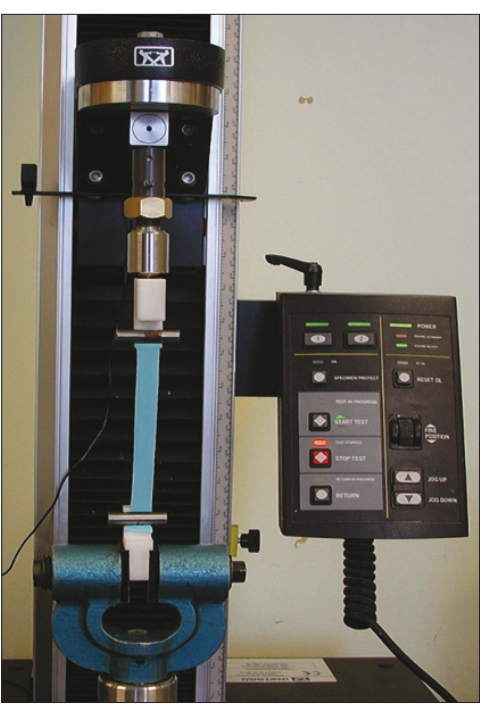

ture probe or pentrometer was driven into the glove specimen at a constant velocity of $508 \mathrm{~mm} / \mathrm{min}$ with the puncture force $(\mathrm{N})$ recorded against the elongation $(\mathrm{cm})$. Each dental examination glove type investigated was assessed separately and glove specimens were taken sequentially from the little finger to the thumb, ending with the palm. The results were saved to a spreadsheet format prior to statistical analysis.

\section{Dental injection needle}

In an attempt to simulate the clinical conditions more accurately the F1342-91, ${ }^{22}$ was adapted and the steel puncture probe used above as the pentrometer was replaced by a hypodermic needle of $0.45 \mathrm{~mm}$ diameter. The needle was connected to the load cell using a specifically designed attachment mimicking the connecting part of a disposable syringe (Fig. 3). The protocol as highlighted above for the steel puncture probe was followed and the dental hypodermic needle (Carpule, Heraeus Kulzer, Osaka, Japan) was changed every six specimens before being discarded as forces recorded in preliminary testing exhibited no statistical significance when a single needle was used up to nine times to puncture five specimens from each glove type.

\section{Specimen aging}

The dental examination glove samples were also aged to investigate whether puncture resistance varied with aging in an attempt to mimic the clinical situation more closely. Aging was carried out according to ISO $188,{ }^{23}$ at $70^{\circ} \mathrm{C}$ for 7 days in an air-circulating oven prior to testing. The puncture resistance experiments outlined above were repeated using both the steel puncture probe and the sterile dental injection needles as the pentrometer.

\section{Modulus (M100) evaluation}

Specimens from the four dental examination glove types investigated (Microtouch latex, Microtouch nitrile, Nitratouch nitrile and Safeskin nitrile) of $12 \mathrm{~cm}$ length and $1.5 \mathrm{~cm}$ breadth were removed from the sections marked in Figure 1. Both sides of the glove were used and smooth edges were ensured using a razor blade and scalpel. The apparatus, identified in Figure 4 was used to clamp both ends of the glove specimen to an Instron tensile testing machine (Instron Model 5544, Buckinghamshire, England). The upper push fit bracket screwed into the moving arm of the machine and the lower push fit bracket was clamped to the base plate. The glove specimen was held to the upper and lower bracket using a steel bar, such that $1 \mathrm{~cm}$ of each end was fixed to the bracket using a push fit mechanism. The tensile testing machine cross-head speed was fixed at $100 \mathrm{~mm} \mathrm{~min}^{-1}$ and the gauge length, namely the distance between the brackets, was set to $10 \mathrm{~cm}$. The force required to elongate the specimen by $10 \mathrm{~cm}$ (100\% of the original length) was recorded and the modulus at this point, known as M100 was calculated. M100 was evaluated using Equation 1 from BS 903A2: 1995 for the physical testing of rubber. ${ }^{24}$

$$
\mathrm{S}_{\mathrm{e}}=\mathrm{F}_{\mathrm{e}} / \mathrm{W}_{\mathrm{t}}
$$

Equation 1

Where $\mathrm{S}_{\mathrm{e}}$ was the given stress $(\mathrm{MPa}), \mathrm{F}_{\mathrm{e}}$ the force $(\mathrm{N})$ noted at the given strain of $100 \mathrm{~mm} / \mathrm{min}, \mathrm{W}$ the width of the narrow portion of the specimen $(\mathrm{mm})$ and $t$ was the thickness of the test length in $(\mathrm{mm})$ measured with a micrometer screw gauge (Moore and Wright, Sheffield, England) accurate to $10 \mu \mathrm{m}$. From each glove type 20 specimens were assessed and further groups of 20 specimens were tested following aging in an air circulating oven for 7 days at $70^{\circ} \mathrm{C}$ in accordance with ISO $188,{ }^{23}$ as outlined above.

\section{RESULTS}

Puncture resistance

Steel puncture probe

The puncture force required to puncture the Microtouch latex glove types was assessed to be significantly lower $(P<0.001)$ than that required to puncture the three nitrile glove types, when using the one way analysis of variance (ANOVA) at the 95\% significance level (Table 2). The mean and standard deviation of the puncture force assessed for the Microtouch latex glove types was $3.39 \pm 0.76 \mathrm{~N}$. The Microtouch nitrile glove types were evaluated to have the highest puncture resistance with an associated mean and standard deviation of $11.31 \pm 2.13$ $\mathrm{N}$ followed by Nitratouch nitrile and Safeskin nitrile which exhibited a mean and standard deviation of $9.53 \pm 1.38 \mathrm{~N}$ and $8.63 \pm 3.30 \mathrm{~N}$, respectively (Table 2 ). The puncture force recorded for each glove type was assessed to increase when the specimens were aged for seven days in an air-circulating oven (Table 2). However, only Microtouch nitrile $(P<0.001)$ and Safeskin nitrile $(P=0.004)$ exhibited a significant increase in the puncture force on ageing with the associated values rising to $15.26 \pm$ $2.00 \mathrm{~N}$ and $11.6 \pm 1.36 \mathrm{~N}$, respectively (Table 2 ).

The general linear model (GLM) univariate analysis technique was used at the 95\% significance level to compare all the data collected using the steel puncture probe, and the analysis technique established that the aging by glove type interaction was significant at $P<0.001$. Therefore the puncture resistance increased on aging and each dental examination glove type was assessed to have a significantly different puncture resistance (Fig. 5a,b).

\section{Dental injection needle}

Using the one-way analysis of variance (ANOVA), at the 95\% significance level, the puncture forces evaluated were discovered to be significantly different between all non-aged glove types except between Nitratouch nitrile and Safeskin nitrile that were assessed to have a mean puncture force of $0.025 \pm 0.006 \mathrm{~N}$ and $0.024 \pm$ $0.005 \mathrm{~N}$, respectively (Table 2$)$. Microtouch latex $(P<0.001)$, Nitratouch nitrile $(P=0.021)$ and Safeskin nitrile $(P<0.001)$ glove specimens were evaluated to have a significantly higher puncture force when aged, when the ANOVA analysis technique at the 95\% significance level was employed. However, Microtouch nitrile gloves exhibited no significant variation in the puncture force 
Fig. 5 Evaluated mean puncture resistance at different positions in four dental examination glove types assessed using a $0.8 \mathrm{~mm}$ stainless steel puncture probe as the pentrometer for (a) non-aged specimens, and (b) aged specimens

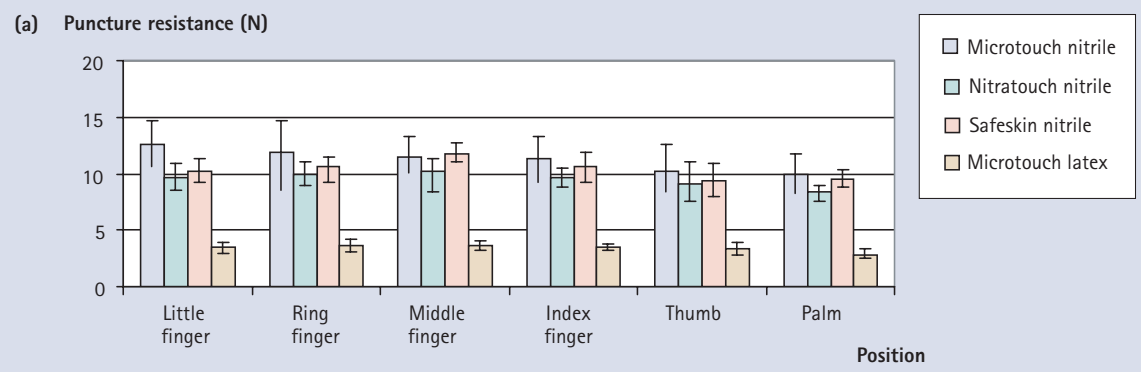

(b) Puncture resistance $(\mathrm{N})$

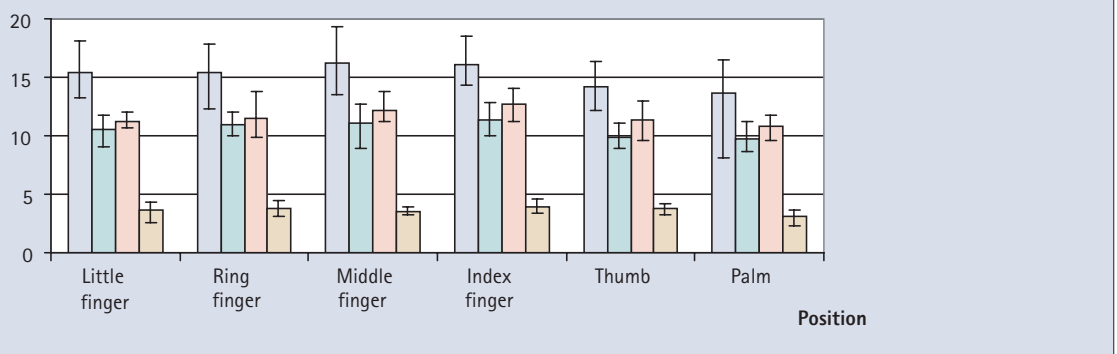

$(P=0.057)$ when comparing non-aged $(0.033 \pm 0.007 \mathrm{~N})$ and aged $(0.036 \pm 0.006 \mathrm{~N})$ glove specimens (Table 2$)$.

The GLM univariate method of analysis was used at the 95\% significance level to compare all data obtained using dental injection needles as the pentrometer. The analysis technique reported an overall increase in the puncture resistance of dental examination gloves when aged $(P=0.004)$. When considering all aged and non-aged data, each glove type was assessed to be significantly different $(P<0.001)$ to the other glove types. The position or site of puncture was also assessed to have a significant effect on the puncture force recorded with post hoc tests highlighting three homogenous subsets containing statistically similar groups (Table 3; Fig. 6a,b). The first group included specimens from the palm region only, the second group included the little, ring and index finger regions as well as the thumb region with the final subset or group comprising specimens from the middle and ring finger regions (Table 3).

\section{Modulus (M100) evaluation}

Using the GLM for the modulus, M100 evaluation data, it was identified that the glove type and aging had a significant effect $(P<0.001)$ on the calculated modulus (Table 4). Three homogenous subsets/similar groups were identified (Table 4) with Safeskin nitrile and Nitratouch nitrile being grouped together and Microtouch nitrile and Microtouch latex making up a separate subset each. Microtouch latex was assessed to have the lowest average modulus value of $0.82 \pm 0.11 \mathrm{MPa}$ when specimens were aged, Microtouch nitrile followed a similar pattern when glove specimens were aged with non-aged mean M100 values of $2.62 \pm 0.48$ $\mathrm{MPa}$ which decreased to $2.54 \pm 0.43 \mathrm{MPa}$ when aged. The modulus for Safeskin nitrile and Nitratouch nitrile increased when speci- mens were aged from $2.69 \pm 0.23$ to $4.24 \pm 0.51 \mathrm{MPa}$ and $3.26 \pm$ 0.33 to $3.53 \pm 0.73) \mathrm{MPa}$, respectively (Table 2). The one-way analysis of variance (ANOVA) at the 95\% significance level suggested that the M100 for aged Microtouch latex and Safeskin nitrile was assessed to be $0.68 \pm 0.09 \mathrm{MPa}$ and $4.23 \pm 0.51 \mathrm{MPa}$, respectively (Table 2). Both values were significantly different $(P<0.001)$ to that calculated for non-aged glove specimens, $0.82 \pm$ $0.11 \mathrm{MPa}$ (Microtouch latex) and 2.69 $\pm 0.23 \mathrm{MPa}$ (Safeskin nitrile).

\section{DISCUSSION}

In the current study, when the steel puncture probe was used, each glove region was assessed to be equally puncture resistant. However differences were observed when the dental injection needle was used as a pentrometer. As outlined in Table 4, the palm regions were evaluated to have a significantly lower puncture resistance followed by the little, ring and index finger regions and the thumb region. The index and middle finger regions were assessed to have a significantly higher puncture resistance than the other regions. However, this may be less relevant in the dental surgery since clinically the fingers come most into contact with sharp instruments that may cause punctures. Murray et al. ${ }^{21}$ suggested that punctures in used dental examination gloves occurred principally in the upper portions of fingers and along the whole length of the thumb. The findings of the current study suggest that the index and middle finger regions were the most puncture resistant, however, as previously reported ${ }^{6,11-13}$ these regions, along with the thumb region, were assessed to be the most common location for punctures.

\section{Puncture resistance}

Steel puncture probe

The puncture forces assessed for all the nitrile glove types investi-

Table 2 Mean puncture resistance and modulus (M100) values for four dental examination glove types investigated

\begin{tabular}{|c|c|c|c|c|c|c|}
\hline \multirow[t]{3}{*}{ Glove type } & \multicolumn{4}{|c|}{ Puncture resistance $(\mathrm{N})$} & \multicolumn{2}{|c|}{ Modulus (MPa) } \\
\hline & \multicolumn{2}{|c|}{ Steel puncture probe } & \multicolumn{2}{|c|}{ Dental injection needle } & \multirow[b]{2}{*}{ Non-aged } & \multirow[b]{2}{*}{ Aged } \\
\hline & Non-aged & Aged & Non-aged & Aged & & \\
\hline Safeskin nitrile & $8.63 \pm 3.3$ & $11.6 \pm 1.36$ & $0.024 \pm 0.005$ & $0.037 \pm 0.006$ & $2.58 \pm 0.36$ & $4.23 \pm 0.51$ \\
\hline Nitratouch nitrile & $9.53 \pm 1.38$ & $10.56 \pm 1.53$ & $0.025 \pm 0.006$ & $0.027 \pm 0.007$ & $3.19 \pm 0.33$ & $3.55 \pm 0.73$ \\
\hline Microtouch nitrile & $11.31 \pm 2.13$ & $15.26 \pm 2.0$ & $0.033 \pm 0.007$ & $0.036 \pm 0.006$ & $2.47 \pm 0.53$ & $2.54 \pm 0.43$ \\
\hline
\end{tabular}




\begin{tabular}{|c|c|}
\hline Glove position & Homogenous subsets \\
\hline Little finger & $B$ \\
\hline Ring finger & $B, C$ \\
\hline Middle finger & C \\
\hline Index finger & $B$ \\
\hline Thumb & $B$ \\
\hline Palm & $A$ \\
\hline \multicolumn{2}{|c|}{$\begin{array}{l}\text { Homogeneous subsets with dissimilar letters highlight statistical } \\
\text { significance }\end{array}$} \\
\hline
\end{tabular}

gated were greater than the forces previously recorded. ${ }^{25-28}$ Fisher et $a{ }^{28}$ reported that the thickness of the glove type was not an accurate predictor of puncture resistance as the thinnest glove assessed, the nitrile glove type, exhibited the highest puncture resistance and recommended the use of nitrile gloves for latexsensitised surgeons. In the current study, the Microtouch latex glove type assessed was the thickest $(0.1778 \mathrm{~mm})$, however, the three nitrile glove types Nitratouch $(0.1143 \mathrm{~mm})$, Safeskin $(0.12446 \mathrm{~mm})$ and Microtouch nitrile $(0.1778 \mathrm{~mm})$ exhibited a significantly higher puncture resistance. In the current study, Microtouch latex gloves exhibited an overall mean puncture resistance of $3.39 \pm 0.76 \mathrm{~N}$ and for specimens from the index finger alone, a mean puncture resistance of $3.51 \pm 0.43 \mathrm{~N}$. This is a higher value than that evaluated for latex examination glove types from previous studies. ${ }^{25-28}$

\section{Dental injection Needle}

Manson et al. ${ }^{29}$ devised a novel method to quantify the force necessary for a representative $0.45 \mathrm{~mm}$ diameter needle to penetrate a glove specimen. The initial and maximal penetration forces were recorded for Biogel latex gloves to be $0.04 \pm 0.01 \mathrm{~N}$ and 0.05 $\pm 0.01 \mathrm{~N}$ respectively, similar to values recorded in the current study. Differences may be explained by the use of different latex glove types, differences in the equipment used to assess puncture resistance and the inherent difficulties in measuring the small forces encountered. Jackson et al. ${ }^{25}$ reported a significantly greater resistance to puncture when a steel puncture probe was

$\begin{aligned} & \text { Table } 4 \text { Homogenous subsets highlighted with } \\ & \text { statistically similar Modulus (M100) values using the } \\ & \text { one-way ANOVA analysis technique at the 95\% } \\ & \text { significance level }\end{aligned}$
$\begin{aligned} & \text { Subset } \\ & \text { Glove type }\end{aligned}$
$\begin{aligned} & \text { Microtouch latex } \\ & \begin{array}{l}\text { Safeskin Nitrile } \\ \text { Nitratouch nitrile }\end{array}\end{aligned}$
$\begin{aligned} & \text { Microtouch nitrile } \\ & \text { Homogeneous subsets with dissimilar letters highlight statistical } \\ & \text { significance }\end{aligned}$

used as opposed to a hypodermic needle. Therefore the authors suggested that the standard should be revised and the hypodermic needle be used to accurately simulate clinical situations. Interestingly, in the current study the Microtouch latex glove type exhibited the lowest and highest puncture resistance when the steel puncture probe and dental injection needle were used, respectively. The nitrile gloves however, ranked in the same order when either type of pentrometer was used. The relative high values obtained for the Microtouch latex glove type when the dental injection needle was used may be explained by the gloves' elastic properties and the ability of the material to reseal punctures as described by Hasma and Othman. ${ }^{30}$ The Microtouch latex glove type was evaluated ${ }^{30}$ to have a significantly lower M100 value compared with the nitrile glove types assessed and the authors postulated that the immediate re-sealing of the latex material provided a further resistance to the needle, a phenomenon perhaps not seen when a steel puncture probe was used due to the larger surface area the re-sealing would have to cover. The puncture resistance increased on aging for all glove types/pentrometer combinations investigated. However, for nitrile gloves this was also accompanied by an increased M100 or stiffness value. Aging the samples involved storing the glove material at $70^{\circ} \mathrm{C}$ for 7 days in an air-circulating oven in accordance with ISO $188^{23}$ and is reported to mimic clinical usage when gloves are worn. However, whilst the standard claims to age the glove specimens, the gloves do not encounter any of the stresses or perspiration associated with routine glove wearing in practice. Following ageing, the heat
Fig. 6 Evaluated mean puncture resistance at different positions in four dental examination glove types assessed using a $0.45 \mathrm{~mm}$ hypodermic needle as the pentrometer for

(a) non-aged specimens, and

(b) aged specimens (a) Puncture resistance (N)

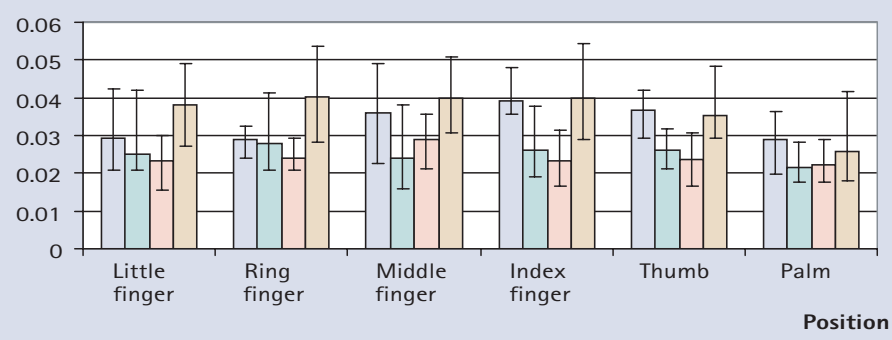

(b) Puncture resistance $(\mathrm{N})$

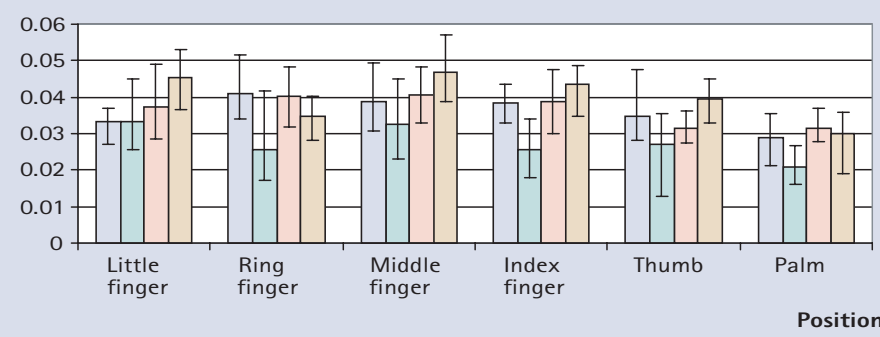

$\square$ Microtouch nitrile $\square$ Nitratouch nitrile $\square$ Safeskin nitrile

$\square$ Microtouch latex 
caused the latex to become less stiff but the difference was not significant. The nitrile gloves however became more stiff, significantly at the 95\% significance level for Safeskin and Microtouch nitrile, manifested as increased M100 values. An associated increased puncture resistance was observed, which correlated to the increased stiffness on ageing.

\section{Modulus (M100) evaluation}

The stiffness, or M100, values evaluated were significantly lower for the Microtouch latex glove type assessed compared with the three nitrile glove types investigated. The nitrile glove types assessed had higher stiffness values, which explained the greater resistance to puncture reported in the current study. The nitrile gloves exhibited superior puncture resistance properties, as stated in studies previously ${ }^{25-28}$ as compared with latex gloves. However, as highlighted by Hasma and Othman ${ }^{30}$ and Checchi et al. ${ }^{31}$ the gloves' elastic properties influence the passage of liquid through punctures. The impressive barrier protection provided by latex gloves was attributed ${ }^{30}$ to the lower modulus of latex and suggested that the risk of infection with punctured nitrile and vinyl gloves might be markedly higher than with punctured latex gloves which have the ability to re-seal due to this low modulus property. The authors proposed that the low modulus enables the latex glove material to stretch partially over the smaller needles of $0.22 \mathrm{~mm}$, $0.25 \mathrm{~mm}$ and to a lesser extent 0.3-0.35 mm needles rather than tear as occurs with vinyl and nitrile glove types. Fisher et al. ${ }^{28}$ identified that one of the two nitrile glove types assessed had a stiffness of $92.9 \mathrm{~N} / \mathrm{m}$; which was significantly greater than the $62.7 \mathrm{~N} / \mathrm{m}$ for the one latex glove type assessed. As the method of stiffness evaluation was different to the current study, comparisons between the figures may not be substantiated, however the general trend was similar to the current study and indicated that the nitrile gloves investigated had a greater stiffness value than the latex gloves assessed.

\section{CONCLUSION}

The three nitrile glove types investigated in the current study were assessed to have significantly higher mean puncture resistance compared with the latex glove type examined when the steel puncture probe was used as a pentrometer. Interestingly the puncture resistance for the latex glove type was assessed to be significantly higher when a dental injection needle was used as the pentrometer compared with the three nitrile glove types. The M100 values were significantly higher for the nitrile glove types for which the stiffness increased when the gloves were aged. This associated higher stiffness evaluated resulted in increased puncture resistance when the nitrile glove specimens were aged irrespective of the pentrometer type used. However, the ability of latex to re-seal itself on puncture may well be more beneficial than the higher puncture resistance of nitrile gloves, when considering the protection potential of each glove type against fluid penetration and therefore associated breaches in cross infection. For the clinician, especially those to have experienced an adverse reaction to natural latex gloves, the results of the current study indicate that an alternative glove type, namely nitrile, is available at reasonable cost and that offers adequate resistance to puncture.

1. Cleveland J L, Lockwood S A, Gooch B F et al. J Am Dent Assoc 1995; 126: 745-751.

2. Palmer G D, Fleming G J P. The management of occupational exposures to blood and saliva in dental practice. Dent Update 2000; 27: 318-324

3. Centres of Disease Control. Recommendations for prevention of HIV transmission in health care settings. Morb Mortal Wkly Rep 1987; 36 (Supp no. 2S) 1-18.

4. Centres of Disease Control. Recommended infection- control practices for dentistry Recommendations and Reports. Morb Mortal Wkly Rep 1993; 42 RR-8: 1-12.

5. Occupational Safety and Health Administration. Occupational exposure to blood borne pathogens. US Department of Labor: 29 CFR Part 1910. Federal Regulation 1991; 56/235: 64004-64182.

6. Katz J N, Gobetti J P, Shipman C. Fluorescein dye evaluation of glove integrity. J Am DentAssoc 1989; 118: 327-331.

7. Ballbach R, Beavin P, Walters S M. A study of testing methods for the detection of defects in disposable latex and plastic gloves. J Assoc Off Analy Chem 1972; 55: 1074-1080.

8. Skaug N. Micropunctures of rubber gloves used in oral surgery. Int J Oral Surg 1976; 5: $220-225$

9. Otis $L \mathrm{~L}$, Cottone $J \mathrm{~A}$. Prevalence of perforations in disposable latex gloves during routine dental treatment. JAm Dent Assoc 1989; 118: 321-324.

10. Siew C, Gruninger $S E$, Miaw $C L$, Neidle E A. Percutaneous injuries in practising dentists; a prospective study using a 20-day diary. J Am Dent Assoc 1995; 126: 1227 1234.

11. Burke FJ T, Wilson N H F, Martin M V, Field EA. Barrier techniques for protection of dental workers and patients-infection control. Dent Update 1990; 24: Supplement 3.

12. Otis $L \mathrm{~L}$, Cottone $J \mathrm{~A}$. Prevalence of perforations in disposable latex gloves during routine dental treatment. J Am Dent Assoc 1989; 118: 321-324.

13. Patton $L L$, Campbell $T L$, Evers S P. Prevalence of glove perforation during double gloving for dental procedures. Gen Dent 1995; 43: 22-26.

14. The Collins English Dictionary, 2nd edn: 1989:867.

15. Dental products spotlight. Nonsterile latex examination gloves. J Am Dent Assoc 2002; 133: 226-227.

16. Amin A, Palenik C J, Cheung S W, Burke F J T. Latex exposure and allergy: a survey of general dental practitioners and dental students. Int Dent J 1998; 48: 77-83.

17. Field $E A$, King $C M$. Skin problems with routine wearing of protective gloves in dental practice. BrDent J 1990; 169: 281-285.

18. Katz J N, Gobetti J P, Shipman C. Fluorescein dye evaluation of glove integrity. J Am Dent Assoc 1989: 118: 327-331.

19. Jackson E M, Neal J G, Williams F M, et al. Biomechanical performance of examination gloves. J Biomed Mater Res 1999a; 48: 193-198.

20. Korniewicz, D M, Laughon, B E, Butz A, Larson E. Integrity of vinyl and latex procedure gloves. Nurs Res 1989; 38: 144-146.

21. Murray C A, Burke FJ T, McHugh S. An assessment of the punctures in latex and nonlatex dental examination gloves in routine clinical practice. Br Dent J 2001; 190: 377-380.

22. American Society for Testing and Materials, F 1342-91. (1996). Standard test for: Protective clothing material resistance to puncture.

23. International Organisation for Standardisation, 188. (1998). Rubber, vulcanised or thermoplastic: Accelerated ageing and heat resistance tests.

24. British Standard 903-A2. (1995). Physical testing of rubber.

25. Jackson E M, Wenger M D, Neal J G, Thacker J G, Edlich R F. Inadequate standard for glove puncture resistance: allows production of gloves with limited puncture resistance. J Emerg Med 1998; 16: 461-465.

26. Jackson E M, Williams F M, Neal J G, Stern CA, Suber F, Thacker J G, Edlich R F. Biomechanical performance of examination gloves. J Biomed Mater Res 1999b; 48 : 572-577.

27. Fisher M D, Reddy VR, Williams F M, Lin KY, Thacker J G, Edlich R F. Biomechanical performance of powder-free examination gloves. J Emerg Med 1999a; 17: 1011-1018.

28. Fisher M D., Reddy VR, Williams F M, Lin KY, Thacker J G, Edlich R F. Biomechanica performance of latex and non-latex double gloving systems. J Biomed Mater Res 1999b; 48: 797-806.

29. Manson T T, Bromberg W G, Thacker J G, McGregor W, Morgan R F, Edlich R F. A new glove puncture detection system. J Emerg Med 1995; 13: 357-364.

30. Hasma H, Othman A B. Barrier performance of natural rubber, vinyl and nitrile gloves on puncture. RAPRA Latex Conference, Munich, Germany. 4-5th Dec, 2001

31. Checchi L., Montebugnoli L., Boschi S., Achille C D. Influence of dental glove type on the penetration of liquid through experimental perforations: A spectrophotometric analysis. Quintessence Int 1994; 25: 647-649. 